\title{
TECNOLOGIA DIGITAL EM BIBLIOTECAS E ARQUIVOS
}

\section{DIGITAL TECHNOLOGYINLIBRARIESANDARCHIVES}

\author{
Ana Maria Rezende CABRAL ${ }^{1}$
}

\begin{abstract}
RESUMO
O artigo apresenta o processo de digitalização da informação como recurso tecnológico moderno que possibilita a conservação e preservação de materiais informativos em bibliotecas e arquivos. Discute aspectos da adoção da tecnologia digital a serem considerados pelas instituições e salienta a necessidade de planejamento para sua implementação, que leve em conta o uso e as demandas de informação dos usuários.
\end{abstract}

Palavras-chave: preservação, tecnologia digital.

\begin{abstract}
This paper presents the digital processing of information as a modern technological tool for conservation and preservation of informative materials in libraries and archives. It also includes some ideas on the employment of digital technology to be considered by institutions and points out the need of planning the uses and demands of users.
\end{abstract}

Key words: preservation, digital technology.

\section{INTRODUÇÃO}

O século XX pode ser considerado como um período de grandes transformações, tendo provocado mudanças decisivas em todas as esferas societárias, tanto em nível político como econômico, social e cultural. O fenômeno da globalização econômica acarretou profundas conseqüências na estrutura dos países, em suas relações sociais e nos modos de produção e trabalho. Por outro lado, verificou-se significativa alteração nos hábitos, valores, comportamentos e estilos de vida, fazendo emergir uma nova c ultura, chamada por alguns autores de pós-moderna, em que os campos das artes, da arquitetura, da literatura e da produção científico-tecnológica foram também afetados.

Toffler (1992) assinala os impactos causados por essa nova fase da história mundial, que ele denomina como "Terceira Onda", onde se observa uma verdadeira revolução tecnológica concentrada nas tecnologias de comunicação e informação.

(1) Professora Adjunta, Escola de Ciência da Informação, Universidade Federal de Minas Gerais. E-mail: acabral@eb.ufmg.br 
Assistimos, na transição da sociedade industrial para a pós-industrial, que a informação se torna objeto propulsor do desenvolvimento, e que o fator deter-minante do progresso dos países se desloca cada vez mais da posse de bens materiais para a capacidade de elaborar e criar bens não-materiais, como informações e quaisquer símbolos que veiculam idéias.

Ou seja, o que hoje determina a riqueza e a hierarquia entre os países não é tão somente o motor das fábricas, mas a engrenagem que move a circulação de idéias, informações e conhecimentos. Portanto, o que se verifica na Sociedade da Informação que desponta a partir da década de 50 , é que o saber adquire o caráter de principal força de produção passando a ocupar posição de mercadoria informacional, imprescindível à competição mundial pelo poder.

Assim, com a globalização, a interdependência das economias, estados e sociedades, distingue-se pelo "modo de informação" em que as tecnologias informacionais alteram as formas de relações sociais, devido, em grande parte, ao novo sistema de comunicação que fala uma língua universal digital.

As redes interativas de computadores crescem surpreendentemente, invadindo o cotidiano das pessoas e modificando substancialmente os antigos parâmetros de tempo e espaço, como também a geopolítica global, ao eliminarem as fronteiras geográficas.

O novo paradigma tecnológico produziu, sem dúvida alguma, alterações nas relações de produção, haja vista as estratégias introduzidas na economia dos países desenvolvidos como Japão, Estados Unidos e centros europeus, as quais resultaram na implantação de fábricas flexíveis e computarizadas que exigem um outro tipo de profissional, com habilidades para manipular e utilizar informações com criatividade. Nesse sentido, o processo produtivo passou a requerer experts treinados no uso competente das tecnologias para criar conhecimentos inovadores e gerar produtos diferenciados e de qualidade, capazes de concorrer num mercado mundial cada vez mais competitivo. Lyotard (1988) afirma que, na sociedade pós-moderna são evidentes as mudanças nos papéis e nas funções da informação e do conhecimento, em que vigora o "princípio de performatividade", significando que saber usar é mais importante que possuir conhecimento pessoal.

Enfim, segundo Webster (1995), uma das marcas da pós-modernidade é o critério tecnológico, que impõe um novo padrão sobre a vida cotidiana, devido ao crescimento da informação com circulação social e um ambiente doméstico mais informatizado. A cultura contemporânea assenta-se, pois, num ambiente saturado de informações onde se observa uma "explosão de significações e sentidos".

Este contexto leva-nos a concluir que as populações em geral devem estar preparadas para utilizar serviços e sistemas associados às redes de comunicação e informação, e educadas para consumir informações e conhecimentos competentemente.

\section{FOCALIZANDO A CONSERVAÇÃO E A PRESERVAÇÃO}

A preservação de materiais em bibliotecas e arquivos sempre foi um desafio para os profissionais dessas instituições, preocupados em ter de enfrentar os mais variados problemas relativos à deterioração de suas coleções e, identificar as prováveis situações responsáveis pelos danos causados aos acervos informacionais sob sua guarda.

Dentre as variáveis que têm sido objeto de avaliação para evitar e eliminar fatores prejudiciais à conservação e preservação de livros, documentos e outros registros, enumeram-se as questões ambientais, de poluição do ar, de composição dos agentes químicos dos materiais, umidade relativa do ar e luminosidade, entre outras.

Desde o século $X X$ reconhece-se que a preservação de acervos é especificamente uma questão administrativa, englobando funções que visam a alcançar economia e eficácia através de ações e intervenções nas etapas de produção, utilização, conservação e destinação de documentos, para isso exigindo a adoção de medidas especiais em relação à prevenção de danos às coleções.

Sendo, pois, um trabalho de natureza administrativa, envolve planejamento baseado em 
decisões políticas e o estabelecimento de programas com atividades de preservação que incluam ações contínuas em torno de um conjunto de medidas voltadas para a reorganização de serviços, atribuição de funções e metodologias de avaliação sistemática do estado das coleções, visando o estabelecimento de estratégias de ação preventivas e corretivas. Tudo isso com a finalidade última de que as variadas formas e formatos preservados possam ser disponibilizados para uso, de acordo com os diversos propósitos do público em geral.

Desta forma, compreende-se que o planejamento deve considerar, também, a melhoria do projeto do espaço físico necessário e apropriado para o adequado acondicionamento dos materiais, assim como, a possibilidade de expansão futura do espaço destinado ao acervo e sua consulta pelos usuários.

\section{Segundo Conway (1997, p.6):}

O gerenciamento de preservação compreende todas as políticas, procedimentos e processos que, juntos, evitam a deterioração ulterior do material de que são compostos os objetos, prorrogam a informação que contêm e intensificam sua importância funcional.

\section{MEIOS TECNOLÓGICOS DE PRESERVAÇÃO}

Ao longo dos tempos, observa-se que os profissionais que lidam com informações têm adotado recursos tecnológicos com potencial para ampliar as possibilidades de preservação dos materiais dos acervos, assim como facilitar o acesso e o uso de suas coleções aos usuários, que são o objetivo fim de qualquer sistema de informação. No entanto, a tomada de decisões sobre a adoção de novos processos de tratamento da informação não é fácil, requerendo muitas discussões sobre suas vantagens e desvantagens, os custos em relação aos benefícios, as prioridades a serem observadas com fins de preservação dos documentos, assim como o gerenciamento das tecnologias adotadas.

Entre os principais aspectos a serem considerados para a adoção de novas tecnologias, problemas tais como o acesso, a longevidade e operacionalidade dos novos sistemas são aqueles que merecem maior discussão no processo de planejamento, e as decisões devem ter em vista políticas mais amplas, em que os profissionais envolvidos devem ser convidados a participar das deliberações.

Segundo Howard (2001), algumas questões cruciais devem ser discutidas em relação à administração de informações, entre as quais destacam-se a missão e os objetivos da instituição (arquivo, biblioteca, museu, etc.), seja ela pública ou privada e, especialmente, questões relacionadas aos usuários, considerando-se que tipo de uso fazem do acervo, o que querem e o que precisam, o que demandam e quais são suas expectativas. Perguntas desse tipo é que poderão nortear o tipo de informação/material a selecionar, as formas de apresentar a informação, e a escolha dos modos de recuperação da informação, como mecanismos de busca, escolha de palavras-chave, entre outros.

Desnecessário lembrar que com o desenvolvimento da Informática a partir da década de 80 , tem-se observado sua crescente utilização em todas as áreas do conhecimento, entre elas a Ciência da Informação, a Biblioteconomia e a Arquivologia. A importância que a disseminação e o uso de computadores pessoais adquiriram por sua comprovada eficiência e agilidade para otimizar ações relativas à preservação documental, assim como os aspectos de acesso, busca e recuperação da informação é indiscutível e, segundo Figueiredo citado por Lombardi (2000, p.420), "Suas aplicações evoluem então do processador de texto para programas de bancos de dados, gráficos, estatísticas e redes de comunicação". $\mathrm{O}$ autor afirma, ainda, que o acelerado uso das novas tecnologias que se vem observando, foi possibilitado pelos seguintes fatores: "barateamento dos microcomputadores, ampliação da memória das máquinas, novos programas mais interativos, integração de vários níveis de informação (como textos, dados, gráficos, tabelas e imagens), etc. (419).

Em decorrência dos avanços tecnológicos, os profissionais da informação (bibliotecários e arquivistas) tiveram que se atualizar e estabelecer sintonia com as mudanças ocorridas em sua área de atuação, tendo em vista que a gestão do 
conhecimento exigiu-lhes preparação técnica para lidar, atualmente, em espaços informacionais digitais: tanto os espaços arquivísticos quanto as bibliotecas digitais. Como profissionais responsáveis pela gestão e preservação de coleções documentais, a utilização adequada das Novas Tecnologias da Informação e da Comunicação (NTIC) em arquivos, bibliotecas e museus, possibilitará o atendimento ágil aos mais diversos tipos de usuários: estudantes, educadores, pesquisadores, artistas, cientistas, profissionais liberais entre outros.

Tais tecnologias permitiram ampliar a disseminação de informações, não apenas em termos de volume e alcance, mas também quanto à forma. Os recursos de multimídia permitiram além do tratamento e disseminação de informações sob a forma de texto, também sob a forma de sons, gráficos e imagens. Segundo Targino (1995, p.197), o termo multimídia

corresponde à multiplicidade de meios, à simultaneidade, à instantaneidade, ou seja, à possibilidade de reunir som, texto e imagens animadas no computador mediante a conexão de microfones, caixas acústicas e CD-ROM.

Independente de uma definição única e precisa, Andrade \& Araújo (2000, p.53) afirmam que como o próprio nome traduz, multimídia compreende vários tipos de mídia, ou seja, vários meios de representação e disseminação da informação, incluindo imagem, gráfico, animação, vídeo, textos livres, áudio, cada qual com suas propriedades específicas. Os autores a consideram como a mais rica e expressiva forma para representar e interagir com a informação, além de tornar a comunicação mais sensorial, multidimensional e não linear, e permitir uma participação mais intensa entre o real e o virtual. De acordo com os autores, "Aplicações multimídia podem ser encontradas onde existe a necessidade de se gerenciar dados complexos" - e, complementam dizendo que

A associação de sistemas de gerência de bancos de dados multimídia com a Internet é de especial interesse para os sistemas de informação direcionados para museus e outras instituições responsáveis pela guarda e divulgação de obras de arte e documentos históricos. Estas tecnologias conjugadas têm um grande potencial para ampliar e democratizar o acesso ao patri-mônio cultural da humanidade.

Apesar da crescente utilização das novas tecnologias na criação de arquivos e bibliotecas digitais, acredita-se ser imprescindível a necessidade de discussões pelos profissionais sobre as abordagens teóricas e metodológicas dessa nova área de pesquisa, e o empreendimento de estudos com outros enfoques, que contemplem não apenas aspectos da recuperação da informação mas, especialmente que adotem uma perspectiva voltada para o usuário, as funções que desempenha e suas demandas específicas. Além disso, devem adquirir um conhecimento profundo sobre as práticas presentes e passadas adotadas em bibliotecas e arquivos, de modo a conceber projetos que se identifiquem com a realidade da organização a que pretendem prestar serviços de informação de qualidade (GUIMAR ÃES, 1995).

\section{ASPECTOS RELACIONADOS À IMPLANTAÇÃO DE BIBLIOTECAS E ARQUIVOS DIGITAIS}

$\mathrm{Na}$ sociedade contemporânea diversas práticas de gerenciamento de recursos informacionais, com base na tecnologia computacional, estão sendo objeto de debate e implementação, tanto no que se refere aos arquivos como às bibliotecas digitais, que têm se apresentado como paradigmas alternativos aos arquivos e bibliotecas "tradicionais", para os serviços de tratamento e disseminação de informações.

Tais acervos podem ser acessados remotamente de quaisquer pontos do planeta, e os documentos "virtuais" disponibilizados online, além de favorecem acessibilidade ilimitada e universal não sofrem mais problemas de sua contraparte física, haja vista sua reprodutibilidade técnica infinita.

Enquanto as tecnologias computacionais e de telecomunicações sofrem modificações cada vez mais rápidas, as bibliotecas e arquivos, em geral, têm sido cada vez mais lentas em sua 
adaptação às mudanças que afetam o gerenciamento de suas coleções. Vários autores têm relacionado os principais pontos a serem observados a fim de se efetuar/implementar tais mudanças, e as novas adaptações administrativas a serem empreendidas. Isso implica em levantamentos que subsidiem um perfeito diagnóstico para o planejamento de criação de bibliotecas e arquivos digitais, com definições precisas sobre seus objetivos e metas, publico real e potencial, redesenho dos serviços oferecidos e funções desempenhadas pelos usuários e informações que demandam para o seu trabalho.

Segundo Guimarães (1995), o planejamento e implantação de bibliotecas digitais (o mesmo servindo para arquivos digitais) devem ser concebidos levando-se em consideração:

a) o contexto político-econômico e sociocultural e aspectos conjunturais do local em que a instituição está inserida, os quais irão influenciar nas decisões a serem tomadas e direcionar os objetivos e estratégias de ação dos serviços de informação; como na globalização econômica as necessidades de informação se modificam e os usuários são cada vez mais exigentes quanto à qualidade e rapidez da informação, cabe ao profissional "filtrar" e selecionar dentro do enorme volume de informações, aquelas mais relevantes na área de assunto específica de interesse do usuário;

b) adequação de novas práticas e procedimentos de gerenciamento e manipulação das coleções;

c) promoção do aperfeiçoamento e treinamento dos profissionais e dos usuários par utilizarem os recursos tecnológicos em todo o seu potencial;

d) desenvolvimento de políticas de seleção/descarte de materiais que auxiliem o profissional a decidir se opera somente com informações digitais, ou também documentos não digitais. Certamente, no acervo de bibliotecas e arquivos terão de coexistir lado a lado os dois tipos de material, devido à impossibilidade de digitalização de informações em suportes físicos muito desgastados, que não permitem manuseio (documentos e obras raras), ou mesmo por se tratarem de suportes físicos não amigáveis às técnicas de transcrição/recodificação de linguagens.

A autora cita também, os principais pontos fracos das coleções digitais, como:

Pode haver resistência por parte dos usuários ao uso das novas tecnologias, por exigirem mudanças no comportamento e estratégias de busca da informação;

A preferência da grande número de pessoas pelos materiais impressos por sua praticidade, flexibilidade no manuseio e uso, além da maior interação propiciada entre o leitor e o autor do texto, através do contato físico com o documento/objeto;

A exigência de treinamento dos profissionais da informação e dos usuários para capacitá-los ao uso pleno dos recursos oferecidos pelas novas tecnologias;

$\mathrm{O}$ risco de que o custo das aquisições não corresponda aos benefícios esperados e não revertam em maior produtividade e eficiência para a organização (GUIMARÃES, 1995).

\section{BIBLIOTECASDIGITAIS}

A literatura sobre bibliotecas digitais demonstra a incipiência desta área de pesquisa, apresentando conceitos imprecisos e divergentes - verifica-se desde autores que definem bibliotecas digital, eletrônica e virtual como instituições de natureza diferente, até aqueles que definem a biblioteca digital como sendo igualmente eletrônica ou virtual, sem distinção entre as três modalidades.

No Brasil várias experiências já se concretizaram e têm sido, inclusive, incentivados "iniciativas, projetos e atividades que visem a geração de metodologias, instrumentos e outros mecanismos que visem coletar e disponibilizar na rede a informação gerada no país" (ZANAGA \& SILVA, 2000). Em 1996 foi criado 
o Grupo de Trabalho em Bibliotecas Virtuais, coordenado pelo Instituto Brasileiro de Informação Científica e Tecnológica (IBICT). Estatísticas de 1998 apresentadas pelo grupo, revelam que dentre as bibliotecas já disponíveis na Internet $64 \%$ são universitárias, sendo que os demais $36 \%$ se distribuem em especializadas, escolares, públicas e nacional (Grupo..., 1998).

Duas experiências interessantes de diferentes tipos podem ser mencionadas, sendo ambas em ambiente WEB: 1) a Biblioteca Virtual da Universidade de Campinas (Unicamp), desenvolvida a partir do banco de dados Acervus do Sistema de Bibliotecas da Unicamp. Num trabalho conjunto de bibliotecários e analistas de sistema, decidiu-se optar pelo software Alta Vista Search Intranet, da Digital Corporation, que além de ser utilizado em aplicações na Internet e oferecer opções para recuperação textual, dispõe de vários recursos aplicáveis à recuperação de informações bibliográficas; 2) a Biblioteca Virtual Anísio Teixeira, inaugurada em 1997 e desenvolvida pelo Programa de Informação para Pesquisa (Prossi$\mathrm{ga} / \mathrm{CNPq}$ ) com o objetivo de disponibilizar em rede mundial o pensamento do educador brasileiro e depoimentos de amigos sobre sua obra. Segundo Nunes (2000, p.22), uma das consultoras participantes do projeto, inúmeras questões relativas à criação da biblioteca virtual foram debatidas em seminários entre as quais, o que se entende pelo termo, seus objetivos, a quem se destina, como se dá a interação, quais os problemas que emergem no processo de sua elaboração e seu impacto junto aos usuários. Concluíram os participantes que " $A$ definição de Biblioteca Virtual depende das preocupações de quem aborda a questão. Quem pensa na comunidade de usuários define a Biblioteca Virtual como um espaço de interação no qual é imprescindivel a rapidez de acesso a conjuntos de documentos de boa qualidade (do ponto de vista e formal), apresentados na integra".

Segundo Kuramoto (2001), a biblioteca digital, mais do que uma simples entidade, ela está associada a um conjunto de tecnologias da informação e da comunicação com o propósito de disseminar as informações associadas a uma coleção ou conjunto de coleções. Dessa maneira, uma biblioteca digital não se restringe a uma coleção específica de uma biblioteca, mas pode reunir coleções de um conjunto de bibliotecas interligadas através de uma rede de computadores. Assim como numa biblioteca convencional, a sua congênere digital oferece o acesso não apenas à informação referencial mas estende-se aos Artefatos Digitais (AD) ou Objetos Digitais (OD) que se referem ao conteúdo integral de quaisquer tipos de materiais digitalizados: fotos, filmes, músicas etc. Os registros (records) dão lugar então aos Objetos Digitais (Digital Objects) que requerem uma série de itens de dados, dentre os quais destacam-se: uma identificação única, lista de transações realizadas, o próprio conteúdo do material, descrição do material utilizando (metadados) padrões internacionais como por exemplo o Dublin Core.

Quanto à sua arquitetura Kuramoto (2001) afirma tratarem-se, as Bibliotecas Digitais, de supersistemas de informação, existindo diversos modelos, desde as mais fechadas - grupo de bibliotecas organizadas com regras, padrões e procedimentos, demandando grande esforço e manutenção de conformidade e cooperação, até as mais abertas e flexiveis que funcionam sem nenhum acordo formal ou estabelecimento de padrões específicos. Esse último modelo funciona à semelhança dos mecanismos de busca como Alta Vista, Infoseek, etc.

Para Nunes (2000), definições acerca do conteúdo e do que disponibilizar nas Bibliotecas Digitais, deverão obedecer a critérios sobre direitos autorais, adequação e viabilidade, recursos financeiros e operacionais e coerência com os objetivos de criação de coletivos inteligentes visando a produção de conhecimento. Outras decisões importantes referem-se a questões técnicas tipo: o que fazer com textos pouco legíveis, como dinamizar o uso das bibliotecas digitais, quantos links colocar em cada página ou em termos de resolução: como tratar fotos e imagens?

Como se verifica, são muito diversificados os aspectos a considerar na implantação de bibliotecas digitais, exigindo sério planejamento a fim de que se torne uma solução realmente inovadora e bem sucedida, que tenha ampla receptividade na organização por parte dos usuários. Além disso, é 
fundamental que seja um trabalho interdisciplinar, realizado em conjunto por profissionais da informação, analistas de sistemas, ergonomistas, administradores, entre profissionais de outras áreas.

\section{ARQUIVOS DIGITAIS}

A definição de Arquivo Público citada por Andrade \& Araújo (2000) e extraída do próprio Guia do Arquivo Público Mineiro de 1993, revela o conceito dado a esta instituição "como o conjunto de documentos produzidos ou recebidos por instituições governamentais em decorrência de suas funções específicas, administrativas, judiciárias ou legislativas", sendo que a mesma fonte define 'documento' como "um registro de informação independente do meio físico que o contém”. Vale ressaltar que além dos arquivos públicos existem também arquivos privados pertencentes a empresas, como também particulares, de colecionadores individuais, por exemplo.

Os arquivos, sejam públicos ou privados podem possuir acervos compostos por documentos variados, incluindo os textuais e especiais como: atas, recortes, cartazes, filmes, fotografias, mapas e plantas. A função do arquivo é recolher, custodiar, e conservar documentos produzidos pela administração, e garantir o acesso dos cidadãos a esse grande volume documental. Apesar de arquivos e bibliotecas poderem possuir classes de materiais idênticos, algumas diferenças básicas devem ser apontadas em relação à forma de aquisição, que nas bibliotecas se dá por compra, doação ou permuta, enquanto no arquivo por transferência ou depósito; o bibliotecário seleciona o material e adquire peças avulsas, o arquivista avalia o material e faz o julgamento da peça em relação às outras, agrupando-as em unidades que são agregados. Portanto, ao avaliar os materiais para fins de preservação, os arquivistas o fazem pelo princípio da proveniência, pelo qual os documentos serão agrupados segundo suas origens. Por outro lado, enquanto os documentos de bibliotecas podem ser repostos por compra, os documentos de arquivo, uma vez destruídos não podem ser recuperados pois, comumente, só existem em uma única via.
Todas estas particularidades exigem métodos e técnicas às vezes diferenciadas de tratamento dos materiais podendo, no entanto, haver abordagens de arranjo que sejam úteis e apropriadas para uso tanto em bibliotecas quanto arquivos, mesmo porque, muitas bibliotecas podem conter arquivos em suas coleções, sejam relativos a pessoas, famílias, instituições ou organizações.

Atualmente, frente às necessidades de preservação de acervos de arquivos, uma questão bastante discutida entre os arquivistas, segundo Andrade (1999, p.99), é sobre que meios de reprodução devem ser adotados na preservação de documentos em idade permanente? Microfilmar ou digitalizar documentos? A autora cita depoimento da Secretária Geral da Fundación Historica Tavera (Espanha), no qual afirma que "a evolução técnica de digitalização tem provocado em muitos casos o replanejamento das estratégias de reprodução documental estabelecidas pelas instituições arquivísticas. $O$ que se justifica nas vantagens que a digitalização apresenta em relação à microfilmagem. Não obstante, a própria evolução contínua e aperfeiçoamento da referida técnica da digitalização tem colocado, ao mesmo tempo, reservas quanto à conveniência de sua aplicação".

É difícil optar por uma ou outra tecnologia, visto que tanto a microfilmagem quanto a digitalização apresentam vantagens e desvantagens, sendo a comprovação de algumas delas ainda duvidosa e imprecisa. Como se sabe, os custos da preservação são altos em termos de pessoal, material e equipamentos e tempo requerido nas operações de reprodução.Com relação à microfilmagem, trata-se de "um processo de reprodução de documentos que visa, fundamentalmente, à preservação documental e não deve ser aplicada apenas para ganhar espaços" (ANDRADE, 1999, p.101). Neste processo, são produzidas imagens fotográficas de documentos em tamanho reduzido. Na função de preservação, a microfilmagem visa conservar as informações de documentos de valor permanente que se encontrem danificados ou sejam de intenso manuseio pelos usuários (ANDRADE, 1999). Neste ponto, a criação de bancos de imagens serve para preservar os documentos originais ao possibilitar o acesso através de outros meios. 
Na década de 70, o microfilme passou a ser largamente usado em arquivos para fins de preservação por sua simplicidade e por não exigir equipamentos muito caros que, além do mais não sofreram grandes modificações ao longo do tempo. Entre outros pontos positivos do microfilme pode-se citar o fato de ser analógico, regulamentado por lei, permite perícia, reprodução em papel e economia de espaço físico. No entanto, apesar da durabilidade que lhe é atribuída, por se tratar de fotografia, requer os cuidados especiais desse tipo de material.

Segundo Amorim (2000, p. 95), apesar das muitas vantagens apresentadas pelo microfilme em termos de preservação, no que se refere ao acesso, são encontrados alguns problemas, tais como: "o microfilme só pode ser lido em locais que possuam um equipamento específico; a leitura é morosa e há dificuldade de se "folhear" o documento; as cópias têm qualidade inferior ao original".

Em Seminário de Arquivos realizado em Belo Horizonte em maio de 2001, o conferencista Howard colocou a digitalização como um processo que serve à preservação e ao acesso de documentos, mas que é bem diferente da microfilmagem e do qual ainda não se tem muita idéia do custo ao longo do tempo. De acordo com Dollar citado por Andrade, (1999),

Entende-se por digitalização a tecnologia que toma uma fotografia eletrônica de um documento em papel (textos, mapas, desenhos de engenharia, e outros semelhantes) e a armazena digitalmente num sistema computacional.Após sua conversão em imagens eletrônicas, através de um 'scannner', esses documentos são indexados, comprimidos e armazenados em discos digitais ópticos. Nos discos óticos, as informações são legíveis por raio lazer utilizando-se softwares de leitura e deciframento de textos-imagem (tipo OCR - Optical Character Recognition), para gravar as informações nos diversos tipos de discos óticos: CD ROM, WORM, Discos Regraváveis.
Em termos de longevidade dos documentos, algumas dúvidas ainda pairam, especialmente com relação à duração da informação digital, que é um assunto ainda em aberto. Frente às muitas incertezas ainda vigentes, deve-se enfatizar a necessidade de uma política de preservação e descarte pelas instituições que pretendem adotar a tecnologia digital, que estabeleça diretrizes gerais e critérios de acordo com a validade dos documentos, ou seja, observando sua tabela de temporalidade.

Um dos principais problemas referentes à custódia de documentos é justamente decidir sobre o que salvar, quem deveria salvar e como poderia salvar. Quanto à longevidade, é preciso registrar dados sobre o formato de arquivo digital utilizado para a primeira difusão e, recomenda-se a separação das imagens dos seus metadados. Com as mudanças de equipamentos ao longo do tempo, o software necessário para ver as imagens pode tornar-se inacessível, assim como apresentar dificuldades a transferência de um arquivo para outro (HOWARD, 2001).

Numa sociedade cada dia mais orientada para a criação e uso de imagens, os sistemas automatizados de recuperação de imagens digitalizadas podem ser considerados como os mais adequados para o armazenamento e posterior recuperação de fotos, filmes, pinturas, e outros documentos gráficos e audiovisuais. Em função desta proeminência adquirida, Howard (2001) aponta algumas considerações-chave para projetos de imagens, em que destaca como de fundamental importância a qualidade da digitalização, a resolução, o nível de detalhe, e a observação dos diferentes modos de digitalizar, conforme o objetivo (que irá determinar o foco, a moldura, etc.).

Esses aspectos devem ser definidos em função dos usuários, ou seja, de acordo com suas necessidades e do tipo de qualidade que precisam, suas aplicações, enfim o que você quer dizer e o que os usuários desejam/têm como objetivo. É preciso pensar a longo prazo sobre a qualidade que será necessária, pois a qualidade muda com o tempo - no futuro as exigências de qualidade provavelmente serão maiores e haverá melhor 
qualidade devido aos avanços da tecnologia, que evolui cada vez mais na produção de equipamentos de melhor qualidade. Portanto, na escolha de ferramentas e processos, não se pode negligenciar sobre o tipo de digitalizacão, técnicas de compressão, links entre arquivos e aplicações interoperacionais no âmbito da instituição.

O uso do scanner exige uma série de cuidados, desde a escolha acertada do equipamento, de acordo com os objetivos de sua aplicação, evitando-se que limitações de fornecimento possam influenciar. É preciso que se busque a mais alta qualidade de digitalização possível, para garantir a durabilidade da imagem, e as melhores representações tonais; para tal, estar alerta às medidas objetivas do uso para determinar o ajuste que deve ser dado ao scanner (não tentar a melhor imagem apenas para o seu monitor). Também o tamanho da foto é superimportante, devendo-se usar escalas que forneçam medidas precisas para indicar o tamanho do original. Ainda, capturar o máximo de metadados/informações sobre o documento e, inclusive, sobre o scanner (especificações técnicas) e processo usado.

Outras considerações importantes: formato dos arquivos e escolha de sistemas interoperacionais. Como no caso das bibliotecas digitais é importante aderir a padrões para a administração de arquivos digitais. Precisamos de bons padrões para registrar de maneira consistente, adotar diretrizes sobre procedimentos, disponibilizar universalmente e facilitar o compartilhamento e intercâmbio de informações, compreendendo melhor as inter-relações entre informações.

Andrade (1999) e Amorim (2001) são a favor da abordagem de sistemas híbridos, que utilizam tecnologias associadas, de modo a aproveitar o que cada uma tem de melhor a oferecer às necessidades de preservação e acesso. Em geral, a microfilmagem é mais indicada para garantir a preservação com qualidade arquivística, enquanto a digitalização eletrônica de imagens facilita a recuperação e otimiza o acesso à informação. Como os empresários da área de Informática, em geral estão voltados para as demandas do mercado e para os interesses das empresas comerciais, seus produtos não atendem adequadamente às especificidades do mundo acadêmico e das instituições culturais sendo pois, necessário, um esforço conjunto para sensibilizar produtores e vendedores incentivo para criar aplicações que atendam estes campos.

\section{CONSIDERAÇÕES FINAIS}

Como se pôde observar a partir das reflexões aqui apresentadas, as novas tecnologias prometem satisfazer as tarefas tradicionais de armazenamento, organização e acesso em bibliotecas e arquivos digitais, não apenas no que se refere a documentos impressos ou manuscritos, mas informações em variados suportes até grandes arquivos multimídia, que podem ser digitalizados e armazenados com segurança. Os recursos tecnológicos apresentam vantagens como economia de espaço e facilidades de leitura, ao reunir documentos dispersos em um mesmo local.

Assim, diante das várias soluções tecnológicas atualmente oferecidas, cabe aos profissionais que trabalham em unidades de informação avaliarem as possíveis vantagens e desvantagens das opções disponíveis no mercado, como também sua eficácia para o atendimento aos usuários, visando a democratização da informação. É também função dos profissionais, promover treinamento para auxiliar os usuários no uso das novas tecnologias para que adquiram autonomia nos processos de busca da informação e fácil acesso às coleções digitalizadas.

Santos (2000, p.28) afirma que com a globalização no fim do século XX e graças aos avanços da ciência, produziu-se um sistema de técnicas presidido pelas técnicas da informação, sistema este que assegura uma presença planetária por meio da cibernética, da informática e da eletrônica. No entanto, o autor comenta que:

a informação instantânea e globalizada por enquanto não é generalizada e veraz porque atualmente intermediada pelas grandes empresas de informação sendo, pois, socialmente excludente por assegurar exclusividades, ou, pelo menos, privilégios de uso. 
Dizard (1998), separa as mídias entre "mídia antiga" (TV, cinema, rádio e impressos) e as "novas mídias" ou mídias eletrônicas (computadores multimídia, CD's ROM, fac-símile portátil, bancos de dados, livros eletrônicos, redes de videotextos, telefones inteligentes e satélites de transmissão direta de TV, discos digitais, telecomputadores e outros).

Estas se utilizam das novas tecnologias de comunicação e informação, que oferecem um leque mais amplo de serviços de informação e entretenimento para os consumidores e são altamente interativos e bidirecionais ((DIZARD, 1998, p.34)

O mesmo autor salienta que na indústria emergente das "novas mídias", a comercialização eletrônica de notícias e informações provocou mudanças no mercado de serviços eletrônicos para o consumidor, que têm questionado se os computadores multimídia satisfarão suas necessidades, se o preço de serviços compensam, assim como em relação à quantidade e qualidade de informação (é bastante, o que falta?). Outras preocupações do autor referem-se às mudanças que a tecnologia acarreta para o uso dos recursos informacionais, assim como ao seu impacto para a democracia - pergunta ele:

será que ela nos tornará mais livres individual e coletivamente, ou poderá anestesiar os indivíduos para a realidade, ao invés de energizar para compreendê-la e agir sobre ela? (DIZARD, 1998, p.45).

Mas, o mais grave problema apontado por Dizard (1998) é o acesso desigual aos recursos tecnológicos devido às desigualdades econômicas, haja vista que apenas as elites sabem usar computadores e deles se beneficiam para seu progresso pessoal e profissional, enquanto um "lumpem proletariado da informação" carece de habilidades e vontade para usar as tecnologias, ficando sem acesso à educação e recursos culturais. Deste modo, considera-se de fundamental importância, o estabelecimento de políticas públicas democráticas para assegurar o direito de acesso universal dos cidadãos às redes de comunicação e informação eletrônicas.

\section{REFERÊNCIAS}

AMORIM, E.D. Arquivos, pesquisa e as novas tecnologias. In: FARIA FILHO, L.M. (Org.). Arquivos, fontes e novas tecnologias: questões para a História da Educação. Campinas: Autores Associados, 2000. p.89-99. (Memórias da Educação).

ANDRADE, A.C.N. Microfilmagem ou digitalização? O problema da escolha certa. In: SILVA, Z.L. Arquivos, patrimônio e memória: trajetórias e perspectivas. São Paulo: UNESP, 1999. Cap.8, p.99-113. (Seminário \& Debates).

ANDRADE, N.S.; ARAÚJO, A.A. Multimídia para acesso a acervos históricos. IP - Informática Pública, Belo Horizonte, v.2, n.1, 2000. p.49-66. (CDE/Prodabel/ $\mathrm{PBH})$.

CONWAY, P. Preservação no universo digital. Rio de Janeiro: Projeto Conservação Preventiva em Bibliotecas e Arquivos; Arquivo Nacional, 1997.

DIZARD, W.D. A nova mídia: a comunicação de massa na era da informação. Rio de Janeiro: Jorge Zahar, 1998.

GRUPODETRABALHODEBIBLIOTECAS VIRTUAIS. Bibliotecas virtuais classificadas por categoria. Disponível em: <http://www.cg.org.bt/gt/ gtbvlestatistica.htm>. Acesso em: 9 out. 1998.

GUIMARÃES, L. Bibliotecas digitais e disseminação da informação. Rio de Janeiro: IBICT, 1995. Dissertação (Mestrado) - Universidade Federal do Rio de Janeiro.

HOW ARD, W.B. Questões básicas a serem consideradas em projetos de digitalização: planejamento, custos, banco de dados e valor de documentos virtuais. In: SEMINÁRIO DE ARQUIVOS, Belo Horizonte, maio de 2001. (Palestra).

KURAMOTO, H. Bibliotecas digitais. Palestra proferida na Escola de Ciência da Informação da UFMG, Belo Horizonte, ago. 2001.

LOMBARDI, J.C. As novas tecnologias e a pesquisa em História da Educação. In: FARIA FILHO, L.M. (Org.). Arquivos, fontes e novas tecnologias: questões para a 
História da Educação. Campinas: Autores Associados, 2000. p.123-149. (Memória da Educação).

LYOTARD, J-F. O pós-moderno. 3.ed. Rio de Janeiro: José Olympio, 1988.

NUNES, C. Biblioteca Virtual Anísio Teixeira: reflexão sobre a experiência. In: FARIA FILHO, L.M. (Org.). Arquivos, fontes e novas tecnologias: questões para a História da Educação. Campinas: Autores Associados, 2000. p.19-30. (Memória da Educação).

SANTOS, M. Por uma outra globalização: do pensamento único à consciência universal. 2.ed. São Paulo: Record, 2000.
TARGINO, M.G. Novas tecnologias de comunicação: mitos, ritos ou ditos? Ciência da Informação, Brasília, v.24, n.2, p.194-203, 1995.

TOFFLER, A.; TOFFER, H. As cores da violência. Folha de São Paulo, 10 de maio de 1992. Caderno MAIS! p.4.

WEBSTER, F. Theories of the information society. London: Routledge, 1995.

ZANAGA, M.P.; SILVA, I.M.P. Disponibilização do catálogo do acervo das bibliotecas da UNICAMP na WEB, utilizando o Altavista Search Intranet. Transinformação, Campinas, v.12, n.1, p.7-10, 2000. 
